\title{
N400s from sentences, semantic categories, number and letter strings?
}

\author{
JOHN POLICH \\ University of Illinois, Champaign, Illinois
}

\begin{abstract}
The N400 component of the event-related brain potential (ERP) was examined by presenting subjects with stimulus series, each composed of seven items. Four different stimulus types were employed: sentences, semantically related words, numbers, and letters. Half of each stimulus series ended appropriately and half ended anomalously, with half of the terminal items for each ending type printed in large letters. Subjects were instructed to read each item of the series and press a button after the last item to indicate whether the series ended normally or oddly. N400 components were observed for all odd-ending series. Large-type endings tended to produce a substantial P300 component which followed and mitigated the preceding negativity effects. Although somewhat different ERP patterns were obtained across stimulus and ending types, it appears that the N400 can be obtained with a variety of stimuli and is followed by a P300 when an explicit categorization of the eliciting stimulus is required.
\end{abstract}

Kutas and Hillyard (1980b) reported a negative-going event-related potential (ERP) component that occurred approximately $400 \mathrm{msec}$ after subjects read sentences presented one word at a time which ended in a semantically anomalous fashion (e.g., "She spread the warm bread with socks"'). This negativity was most prominent at the center of the scalp ( $\mathrm{Cz}$ electrode site) and was originally thought to reflect the subject's "reprocessing" of the aberrant sentence ending. Subsequent studies found that the $\mathrm{N400}$ or $\mathrm{N} 4$ potential is larger when recorded over the left compared to right hemisphere and is unaffected by the probability of the eliciting stimulus (Kutas \& Hillyard, 1980a, 1980c, 1982). More important, additional sentence-reading-task studies demonstrated that the N4 is most apparent only when semantic rather than grammatical anomalies are presented (Kutas \& Hillyard, 1983), and that its amplitude increases as an inverse function of the subject's expectancy for the terminal word (Kutas \& Hillyard, 1984). These results suggested that the N4 may reflect processes of semantic priming or activation during natural sentence reading (Neville, 1985).

Several other investigators employing a variety of semantic processing tasks also reported N4 components. In general, a classification task based on semantic relationships between stimulus items has been used to elicit the N4 (e.g., Fischler, Bloom, Childers, Arroyo, \& Perry, 1984; Fischler, Bloom, Childers, Roucos, \& Perry, 1983; Harbin, Marsh, \& Harvey, 1984; Neville, Kutas, \& Schmidt, 1982). Other judgment paradigms using verbal

This research was funded by AFOSR Grant F49620-79-C-0233 and by the NIMH Psychophysiology Training Program \#15128-001. Sincere thanks to Emanuel Donchin for his support of this and many other endeavors. Address correspondence to J. Polich, Division of Preclinical Neuroscience, Scripps Clinic and Research Foundation, $10666 \mathrm{~N}$. Torrey Pines Road, La Jolla, CA 92037. stimuli yielded negative waves, similar to the $\mathrm{N4}$, and generated the P300 or P3 ERP component which typically followed the negative-going potential (e.g., Bentin, McCarthy, \& Wood, 1985; Boddy \& Weinberg, 1981; Polich, Vanasse, \& Donchin, 1981; Pritchard, Coles, \& Donchin, 1982; Sandquist, Rohrbaugh, Syndulko, \& Lindsley, 1980). Although the morphology of the N4-like potentials from these reports may be a variation of the N2 component often observed in conjunction with the P3, major task differences between the sentence-reading and verbal-judgment tasks used to produce the various components preclude a firm conclusion as to waveform similarity or difference between these studies.

Polich (in press) attempted to clarify the relationship between the N4 and P3 by comparing the sentence-reading task and a semantic-classification task. Subjects were required either to read the stimulus materials or to make a button-press judgment response about the ending word of the sentences or semantic series used in the categorization task. Waveforms from the reading condition demonstrated N4 components in both the sentence and semantic classification tasks very similar to those reported by Kutas and Hillyard (1980a, 1980b, 1980c, 1982) employing essentially identical procedures for sentence materials. When subjects made an explicit judgment about the sentence and word-series endings, a clear negativegoing potential at $400 \mathrm{msec}$-morphologically similar to those obtained under the reading condition but followed by a robust P3 component-was obtained. These negative components were interpreted as the $\mathrm{N} 2$ potential. Comparison with the components from the reading condition further suggested that the N4 obtained in that paradigm was, in fact, the $\mathrm{N} 2$ generated by semantic judgments as implied by several previous studies (e.g., Bentin et al., 1985; Polich et al., 1981; Sandquist et al., 1980). 
The purpose of the present study was to extend this approach by applying the reading paradigm to stimulus items that could form a logical series but suggest little semantic association among themselves. In addition to sentences and semantically related words, number and letter series which did or did not end logically also were presented. Furthermore, half the stimulus sequences ended in a type size twice as large as the remaining items. Since this latter manipulation tends to produce a post-N4 positive-going waveform in the sentence-reading task (Kutas \& Hillyard, $1980 \mathrm{a}, 1980 \mathrm{c}$ ), it was included in order to compare the effects of stimulus parameters across studies.

\section{METHOD}

\begin{abstract}
Subjects
Twelve subjects were solicited from the university community and received payment for their participation. All subjects were right handed and were native speakers of the English language. Several subjects had had previous experience with ERP experiments although none had participated in the present tasks.
\end{abstract}

\section{Stimuli}

Four different types of stimulus materials, each consisting of a series of seven items with a total of $\mathbf{8 0}$ different series, were constructed for each condition. In the sentences condition, seven-word sentences were composed such that the first six words of each sentence were syntactically and semantically correct. In $\mathbf{4 0}$ sentences, the seventh word was semantically appropriate to the previous six words, but, in the remaining 40 sentences, the seventh word was semantically inappropriate (e.g., "I take coffee with cream and sugar," vs. "She spread the warm bread with socks"'). The semantic categories condition was constructed from different word series in which the first six words belonged to the same semantic category of items (e.g., all words were flower names, all words were fruit names, etc.). For half the series, the seventh word belonged to the same semantic category; in the other half, the seventh word was unrelated to the previous six words. The word series were constructed by selecting six and seven successive members from each semantic category listed in normative sources (Battig \& Montague, 1969; Rosch, 1975). The number series condition was constructed from numbers which defined an easily induced series (e.g., 2, 4, 6, 8, etc.), with the seventh number completing the series correctly for half the number sets and incorrectly for the other half. The letter series were similarly derived from letters which formed an alphabetically determined series (e.g., A, B, C, D, etc.). Half the letter series ended correctly, and the other half did not.

For each of the different stimulus conditions, half of the seventh items for each ending type (i.e., normal vs. odd) was presented in a typeface approximately twice the size of the preceding six items, whereas the remaining seventh items were presented in the same size typeface as the preceding items. Thus, for each stimulus condition, four different types of endings were presented to each subject: (1) normal (correctly) ending, (2) normal-large type ending, (3) odd (anomalously) ending, and (4) odd-large type ending.

\section{Procedure}

Subjects were seated comfortably in front of a cathode ray tube (CRT) (Hewlett Packard 1310A). A viewport tube was attached to the CRT console and served to maintain a constant viewing distance. Subjects were presented with the following sequence of events: A fixation stimulus consisting of five Xs appeared for $1 \mathrm{sec}$ in the middle of the CRT. Following a 1-sec delay, seven stimulus items were presented for $200 \mathrm{msec}$ in the same position, one occurring every $533 \mathrm{msec}$. A period or dot was not presented at the end of any stimulus series.

The intertrial interval was $2 \mathrm{sec}$ for all four conditions. Subjects were instructed to maintain a constant fixation from the onset of the warning stimulus throughout the final item's presentation. Subjects were told to read the material silently and to press one of two hand-held buttons. Half the subjects used their right hands to indicate a normal ending and their left hands to indicate an odd ending; half the subjects had the opposite arrangement. The instructions emphasized that the subjects should read carefully all items of a series and make accurate judgments. Each stimulus series was presented in blocks of 80 trials, with the order of presentation counterbalanced across subjects. The 80 sequences for each stimulus were individually randomized for each subject.

\section{Data Acquisition}

Electroencephalographic activity (EEG) was recorded from the Fz, $\mathrm{Cz}$, and $\mathrm{Pz}$ electrode positions (10-20 International System) referred to linked mastoids. Burden $\mathrm{Ag} / \mathrm{AgCl}$ electrodes were used for the scalp EEG recording with Beckman Biopotential electrodes used as grounds placed laterally and supraorbitally on the right eye. Electrode impedance was always less than $10 \mathrm{k} \Omega$.

The EEG and electro-oculogram (EOG) were amplified with Van Gogh Model 50000 amplifiers using a 10-sec time constant and 35- $\mathrm{Hz}$ upper half-amplitude frequency bandpass. The data were digitized every $10 \mathrm{msec}$ for $5,231 \mathrm{msec}$ beginning $100 \mathrm{msec}$ prior to the stimulus presentation. Experimental control and data acquisition were governed by a PDP-11/40 computer. The EEG and EOG were monitored on-line using a GT44 display. Digitized single-trial data and response accuracy were stored on digital magnetic tape for off-line analysis. EEG epochs were monitored for EOG artifact, and contaminated records were excluded from all analyses.

\section{RESULTS}

Waveforms from the $\mathrm{Cz}$ electrode for each series type and stimulus condition averaged over all subjects are presented in Figure 1. The critical seventh item in the series is denoted as the "target word" at the bottom of the figure, although Arabic numbers and English letters were presented in those conditions rather than words per se. While the instructions emphasized that the subject was not to make a speeded judgment, reaction time (RT) was collected. The mean RT and percent error for each stimulus condition are presented in Table 1 .

The waveform patterns illustrated in Figure 1 are highly similar to those obtained with other paradigms presenting seven-item stimulus series. For each of the odd-ending stimulus conditions (ODD and ODD-L), a negative-going component at approximately $400 \mathrm{msec}$ is evident. This component was found across all three electrodes and was of maximum amplitude at the central and frontal sites. The morphological characteristics of this waveform, especially for the sentence condition, suggest that it is the N4 potential. This negativity was consistently followed by a robust positive component whose scalp distribution was maximal at the parietal electrode sites and can be identified as a $\mathrm{P} 3$ potential. The magnitude of the $\mathrm{N} 4$ effect appears strongly determined by the strength of the subsequent positivity from the P3: As the amplitude of the P3 increases, the amplitude of the N4 diminishes for the odd-ending conditions. This result was also obtained across stimulus materials as well as within a stimulus set for the odd and odd-large items.

For the normal and normal-large stimulus endings (NORM and NORM-L), a less consistent waveform portrait emerged. The normal-large stimulus items generally demonstrated poor morphology for the terminal ERPs 

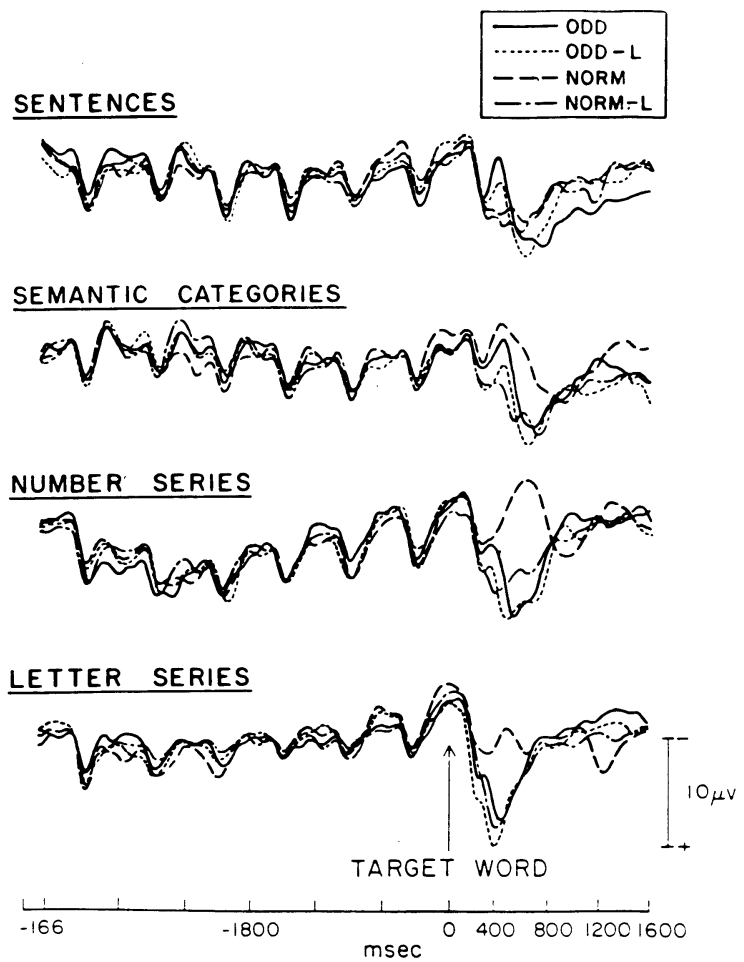

SUPERAVERAGES $(N=12)$

Figure 1. Event-related potential waveforms averaged over all subjects obtained from presenting seven-item series of different stimulus materials. "Target Word" refers to the last stimulus item which completed the series either normally (NORM) or anomalously (ODD) in either the same type size as the preceeding items or in a larger type size (NORM-L, ODD-L).

across stimulus materials except for the letter series, for which a strong P3 component was obtained. While similar positive-going potentials can be found in the other stimulus sets for this ending type, they are not as pronounced in their positivity. Moreover, no clear N4 component was obtained for the normal-large terminal items with any of the stimulus materials.

In contrast, the normal-ending, regular-type stimulus items all demonstrated a negative-going potential at about 400 -msec latency. While the morphology of this component was less consistent across stimulus materials (especially for the sentence items), it did share the central and frontal maximum amplitude distribution observed for the

Table 1

Mean Reaction Time (RT) and Percent Incorrect Responses (IR) for each Stimulus Series, Ending, and Type Size Condition

\begin{tabular}{|c|c|c|c|c|c|c|c|c|}
\hline & \multicolumn{4}{|c|}{ Normal Ending } & \multicolumn{4}{|c|}{ Odd Ending } \\
\hline & \multicolumn{2}{|c|}{ Regular* } & \multicolumn{2}{|c|}{ Large* } & \multicolumn{2}{|c|}{ Regular* } & \multicolumn{2}{|c|}{ Large* } \\
\hline & RT & IR & RT & IR & RT & IR & $\mathrm{RT}$ & IR \\
\hline Sentences & 923 & 2.5 & 896 & 2.6 & 1024 & 4.8 & 950 & 6.3 \\
\hline Categories & 1061 & 6.4 & 998 & 8.3 & 955 & 3.1 & 895 & 3.6 \\
\hline Numbers & 1128 & 8.0 & 945 & 5.6 & 904 & 7.6 & 865 & 21.1 \\
\hline Letters & 920 & 2.1 & 781 & 1.8 & 799 & 17.1 & 758 & 17.3 \\
\hline
\end{tabular}

*Type size. odd-ending terminal items. However, unlike the negative waves observed for the odd-ending items, those obtained to the normal-ending, regular-type-size stimuli were not followed by a clear positivity or P3 component. Indeed, for the semantic categories, number, and letter series, it appears that the terminal item for this ending type yielded only a striking negativity without any subsequent strong positive-going waveform as seen in the odd-ending items of both the regular- and large-type-size stimulus sets.

\section{DISCUSSION}

These results ae highly similar to previous ERP data collected by presenting subjects with seven items and requiring an explicit classification of the terminal item (Polich, in press). In general, the N4 component was consistently followed by a $\mathrm{P} 3$ potential for all but the normalending, regular-type-size series endings. Given the overall pattern of the present effects and agreement with previous findings, it is reasonable to conclude the 400 -msec negativity observed here is an N2 component followed by the typical P3.

This interpretation of these $400-\mathrm{msec}$ negativities is consisent with the view that the $\mathrm{N} 2$ is an initial indication of a mismatching event in the stimulus environment (Pritchard et al., 1982; Ritter, Simson, \& Vaughan, 1983). Thus, the $\mathrm{N} 2$ and $400-\mathrm{msec}$ negative potentials may be invoked by variegated task circumstances because they reflect essentially the same processing mechanism in a manner similar to that suggested for the P3 component whenever memory is updated (Donchin, 1981). The present results support this view and extend it with the findings from the normal-ending, regular-size type series. As the RT data suggest, subjects took the longest time to determine whether the normal-ending number series were indeed normal. The largest negativity across subjects was also obtained in this condition (with similarly conspicuous negative potentials observed in the other stimulus series). This pattern implies that evaluative difficulty of a mismatching event may be reflected by increases in the amplitude of the N2 (Fischler et al., 1984; Fitzgerald \& Picton, 1983; Harbin et al., 1984) as has been found for semantic judgments with the N4 (Kutas \& Hillyard, 1984). Although sensitive to alterations in semantic relationships, the N2/N4 potential appears to reflect violations of complex similarities and dissimilarities among a variety of stimulus items rather than being a unique response to semantic incongruities.

\section{REFERENCES}

Battig, W. F., \& Montague, W. E. (1969). Category norms for verbal items in 56 categories: A replication and extension of the Connecticut category norms. Journal of Experimental Psychology Monographs, 80(3).

Bentin, S., McCarthy, G., \& Wood, C. C. (1985). Event-related potentials, lexical decision and semantic priming. Electroencephalography \& Clinical Neurophysiology, 60, 343-355.

BODDY, J., \& WEINBERG, H. (1981). Brain potentials, perceptual mechanisms, and semantic categorization. Biological Psychology, 12, 43-61.

Donchin, E. (1981). Surprise!... Surprise? Psychophysiology, 18, 493-513.

Fischler, I., Bloom, P. A., Childers, D. G., Arroyo, A. A., \& PerRy, N. W. (1984). Brain potentials during sentence verification: Late negativity and long-term memory strength. Neuropsychologia, 22, 559-568.

Fischler, I., Bloom, P. A., Childers, D. G., Roucos, S. E., \& Perry, N. W. (1983). Brain potentials related to stages of sentence verification. Psychophysiology, 20, 400-409.

Fitzgerald, P. G., \& Picton, T. W. (1983). Event-related potentials recorded during the discrimination of improbable stimuli. Biological Psychology, 17, 241-276.

Harbin, T. J., Marsh, G. R., \& Harvey, M. T. (1984). Differences in the late components of the event-related potential due to age and to semantic and non-semantic tasks. Electroencephalography \& Clinical Neurophysiology, 49, 461-475. 
Kutas, M., \& Hillyard, S. A. (1980a). Event-related brain potentials to semantically inappropriate and surprisingly large words. Biological Psychology, 11, 99-115.

Kutas, M., \& Hillyard, S. A. (1980b). Reading between the lines: Event-related brain potentials during natural sentence processing. Brain \& Language, 11, 354-373.

Kutas, M., \& Hillyard, S. A. (1980c). Reading senseless sentences: Brain potentials reflect semantic incongruity. Science, 207, 203-205.

KuTAS, M., \& Hillyard, S. A. (1982). The lateral distribution of eventrelated potentials during sentence processing. Neuropsychologia, 20 , 579-590.

KUTAS, M., \& HillyaRD, S. A. (1983). Event-related brain potentials to grammatical errors and semantic anomalies. Memory \& Cognition, 11, 539-550.

KUTAS, M., \& HillyaRD, S. A. (1984). Brain potentials during reading reflect word expectancy and semantic association. Nature, $\mathbf{3 0 7}$, 161-163.

NeVille, H. J. (1985). Brain potentials reflect meaning in language. Trends in Neuroscience, 8, 91-92.

NeVille, H. J., KuTAS, M., \& SCHMIDT, A. (1982). Event-related potential studies of cerebral specialization during reading. I: Studies of normal adults. Brain \& Language, 16, 300-315.
Polich, J. (in press). Semantic categorization and event-related potentials. Brain \& Language.

Polich, J., Vanasse, L., \& Donchin, E. (1981). Category expectancy and the N200. Psychophysiology, 2, 142.

Pritchard, W. W., Coles, M. G. H., \& Donchin, E. (1982). N200 amplitude as a function of degree of mismatch in a word categorization paradigm. Psychophysiology, 19, 580.

Ritter, W., Simson, R., \& Vaughan, H. G. (1983). Event-related potential correlates of two stages of information processing in physical and semantic discrimination tasks. Psychophysiology, 20, 168-179.

Rosch, E. (1975). Cognitive representations of semantic categories. Journal of Experimental Psychology: General, 104, 192-233.

SANDQuist, T. F., Rohrbaugh, J. W., Syndulko, K., \& LindSley, D. B. (1980). Electrocortical signs of levels of processing: Perceptual analysis of recognition memory. Psychophysiology, 17, 568-576.

(Manuscript received for publication April 22, 1985.) 